\title{
Mucinous cystadenoma of the appendix in a patient with systemic lupus erythematosus
}

\author{
Debrah A Wirtzfeld MD ${ }^{1}$, Lorne M Price MD FRCPC ${ }^{2}$, Maire A Duggan MD FRCPC ${ }^{3}$, Shaun AC Medlicott MD FRCPC ${ }^{3}$, \\ Francis R Sutherland MD FRCSC ${ }^{1}$
}

DA Wirtzfeld, LM Price, MA Duggan, SAC Medlicott, FR Sutherland. Mucinous cystadenoma of the appendix in a pateint with systemic lupus erythematosus. Can J Gastroenterol $1998 ; 12(8): 573-576$.

A 38-year-old female with systemic lupus erythematosus presented with abdominal pain, diarrhea and iron-deficient anemia. Computed tomogram showed a $2 \times 4 \mathrm{~cm}$ inhomogeneous lesion of the right adnexa. An unusual mass was identified extending from the appendiceal orifice at colonoscopy, and an $8 \mathrm{~cm}$ tubular appendix, apparently prolapsed into the cecum, was identified at celiotomy. An appendectomy with cecectomy was performed. On cut section, mucin was extruded from the lumen of the appendix. A mucinous neoplasm of the appendix with mucinous dissection to the serosal surface was reported at the time of frozen section. No gross ovarian pathology or peritoneal implants were noted. Cystadenoma with associated mucocele formation was verified by permanent histology. Mucocele of the vermiform appendix is a rare condition associated with neoplastic transformation in approximately $75 \%$ of all cases. Benign mucinous cystadenoma of the appendix should be differentiated from cystadenocarcinoma by frozen section at the time of celiotomy to ensure appropriate treatment. While systemic lupus erythematosus can lead to cutaneous mucinosis, an association with mucinous cystadenoma of the appendix has not been previously reported. Surveillance for metachronous colonic neoplasms is warranted in patients diagnosed with a mucinous neoplasm of the appendix.

Key Words: Mucinous cystadenoma, Mucocele, Systemic lupus erythematosus

\section{Cystadénome mucineux de l'appendice chez} une patiente souffrant de lupus érythémateux systémique

RÉSUMÉ: Une femme de 38 ans atteinte d'un lupus érythémateux systémique se présente pour douleurs abdominales, diarrhée et anémie ferriprive. La tomodensitométrie révèle une lésion inhomogène de $2 \mathrm{~cm}$ sur 4 aux annexes droites. Une masse inhabituelle prenant naissance au niveau de l'orifice de l'appendice a été identifiée à la colonoscopie et, à la coliotomie, on a également observé un appendice tubulaire de $8 \mathrm{~cm}$, apparemment en prolapsus vers le cæcum. Une appendicectomie avec typhlectomie à été effectuée; l'examen du spécimen, de la mucine est extrudée de la lumière de l'appendice. Une néoplasie mucineuse de l'appendice avec dissection mucineuse de la surface séreuse est confirmé à l'examen de la section congelée. Aucune pathologie ovarienne macroscopique ni atteinte péritonéale n'a été notée. Le cystadénome compliqué d'un mucocèle est vérifié par histologie permanente. Le mucocèle de l'appendice vermiforme est une maladie rare associée à la transformation néoplasique dans environ $75 \%$ de tous les cas. Il faut distinguer le cystadénome mucineux bénin de l'appendice du cystadénocarcinome en recourant à la section congelée au moment de la coliotomie afin de l'assurer que le traitement approprié soit instauré. Le lupus érythémateux systémique peut entraîner une mucinose cutanée, mais on ne l'avait encore jamais associé au cystadénome mucineux de l'appendice. La surveillance des néoplasies du côlon asynchrones s'impose chez les patients qui ont un diagnostic de néoplasie mucineuse de l'appendice.

Departments of ${ }^{1}$ General Surgery, ${ }^{2}$ Internal Medicine and ${ }^{3}$ Pathology, University of Calgary, Calgary, Alberta

Correspondence: Dr Lorne Price, Room 711 South Tower, 3031 Hospital Drive Northwest, Calgary, Alberta T2N 2 T8.

Telephone 403-283-6613, fax 403-270-7722

Received for publication January 13, 1998. Accepted August 12, 1998 
$\mathrm{M}$ ucocele of the appendix is defined as gross enlargement due to accumulation of intraluminal mucus (1). It is a rare entity, occurring in $0.1 \%$ to $0.7 \%$ of appendectomy specimens $(2,3)$. Three mechanisms have been proposed for mucocele formation (4). A simple mucocele, retention cyst results from mechanical obstruction of the lumen and secondary infection; the epithelial lining is normal or consists of granulation tissue. A second mechanism involves focal or diffuse hyperplasia of the mucosal surface with a resulting mucocele. Finally, neoplastic change may result in cystic dilation of the appendix associated with either obstruction or mucus secretion secondary to the neoplasm itself. We report a case of mucinous cystadenoma with mucocele formation in a patient with systemic lupus erythematosus (SLE).

\section{CASE PRESENTATION}

A 38-year-old female with a two-year history of SLE and iron-deficient anemia presented with a one-year history of epigastric abdominal pain and diarrhea. The pain was intensified by eating and associated with intermittent nausea and vomiting. The symptoms were initially attributed to lupusassociated serositis. There was minimal response to steroid treatment, although her symptoms intensified when this medication was tapered. Physical examination revealed moon facies and abdominal striae consistent with high dose steroid treatment, The patient was minimally tender in the epigastric region. No abdominal masses were noted, and the stool was negative for occult blood.

An abdominal ultrasound revealed a $5 \times 6 \mathrm{~cm}$ cystic structure of the right adnexa, and computed tomogram showed a $2 \times 4 \mathrm{~cm}$ oblong mass in the area of the right adnexa (Figure 1). Diffuse thickening of the bowel wall and a moderate amount of ascites were noted. At colonoscopy, an unusual mass was seen protruding into the cecum from the appendiceal orifice (Figure 2). The mass was approximately $2 \mathrm{~cm}$ in length and appeared cylindrical. The overlying mucosa was relatively normal, with what appeared to be the appendiceal orifice located at its distal extent. Biopsy showed normal colonic mucosa with focal edema, but an appendiceal mucocele was suspected.

At celiotomy, the appendix was tubular and measured approximately $8 \mathrm{~cm}$ in length from the appendiceal base to distal tip. Palpation of the cecum revealed an intraluminal mass apparently extending from the appendix. An extended appendectomy including removal of the cecum was performed. On cut section, mucus was extruded from the distended lumen of the appendix. Frozen section revealed a mucinous neoplasm of the appendix, indicating a differential diagnosis of mucinous cystadenoma versus cystadenocarcinoma. Grossly, the appendix appeared to have partially intussuscepted into the cecum at its base. Permanent histology showed that the appendix was partially replaced with a mucinous tumour (Figure 3). Focal areas of severe dysplasia were noted. Mucosal invaginations were present, but the tumour did not invade the muscularis propria. Large mucin lakes were present within the mucosa and on the serosal surface.

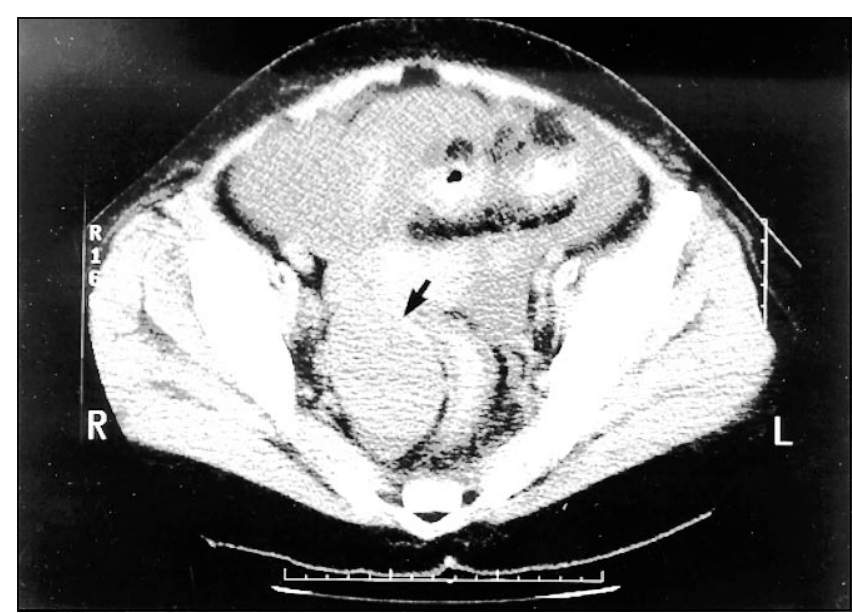

Figure 1) Computed tomogram of the patient's mucinous cystadenoma of the vermiform appendix. A $2 \times 4 \mathrm{~cm}$ oblong mass is located in the area of the right adnexa

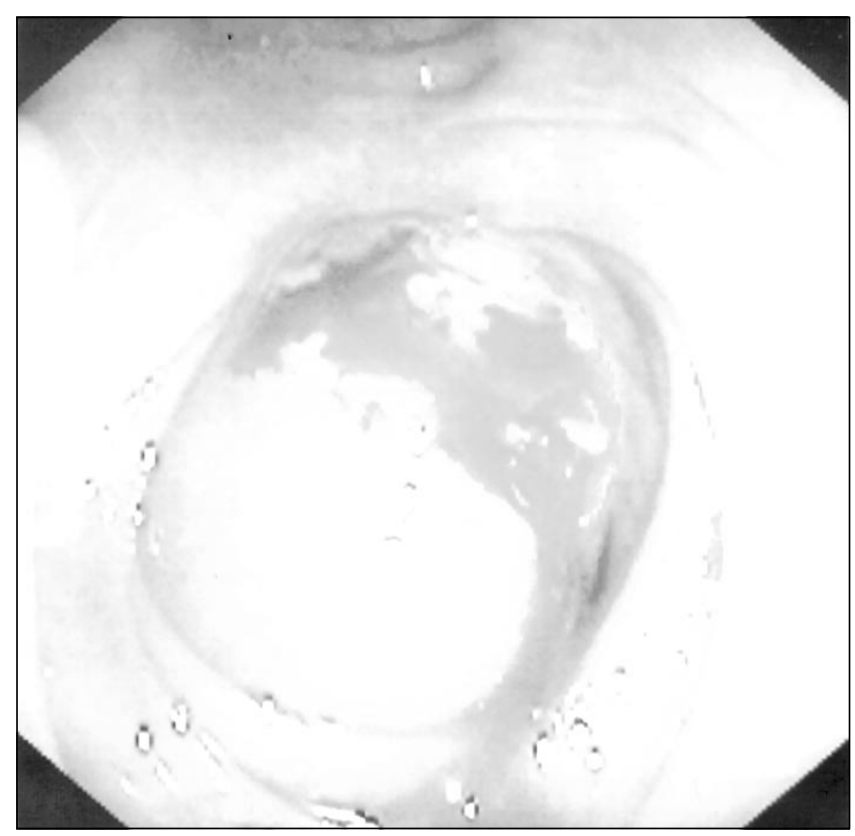

Figure 2) Colonosocpy of the patient's mucinous cystadenoma of the vermiform appendix. An unusual mass is protruding into the cecum from the appendiceal orifice

These did not represent invasive tumour deposits because there was no associated dysplastic mucosal epithelium. The resection margin was free of tumour. There was no evidence of ovarian pathology or peritoneal implants.

\section{DISCUSSION}

Mucocele of the appendix is a rare entity. The patient is often asymptomatic, the lesion being picked up by imaging studies done for other reasons. The patient may complain of right lower quadrant pain, or a palpable mass may be present (2). A cystic mass may be identified by ultrasound or computed tomogram. 
A mucocele of the vermiform appendix may arise from diffuse or localized mucosal hyperplasia, a mucinous cystadenoma or cystadenocarcinoma. A retrospective analysis of 73 mucoceles of the appendix showed that 18 (25\%) were associated with either focal or diffuse hyperplasia of the mucosa with no associated atypia (2). Mucinous cystadenoma was reported in 46 specimens (63\%). The remaining nine lesions (12\%) were cystadenocarcinomas. A second study showed that two of $33(6 \%)$ hyperplastic polyps were associated with the formation of mucoceles (5). Conversely, 32 of 35 (91\%) mucinous cystadenomas and four of five (80\%) mucinous cystadenocarcinomas resulted in mucoceles. A smaller study of 10 mucoceles showed that eight were associated with mucinous cystadenoma and two were associated with mucinous cystadenocarcinoma (6). Therefore, $75 \%$ of mucoceles are associated with neoplastic transformation, while greater than $80 \%$ of mucinous neoplasms result in mucocele formation.

There are no gross features of the appendix that differentiate benign from malignant lesions (2). Therefore, frozen sections should be obtained at the time of celiotomy. Histologically, cellular atypia may be similar between benign and malignant lesions. Diagnosis of malignancy requires invasion of neoplastic epithelial cells, with or without mucin, beyond the submucosal layer. The presence of acellular mucin deep within the appendiceal wall or on the serosal surface is postulated to result from increased intraluminal pressure and can be seen with benign mucinous cystadenomas (4). If a mucinous cystadenocarcinoma is found, a right hemicolectomy should be performed because it has been shown to enhance survival (7).

Microscopic mucin deposition within the dermis has been described in patients with connective tissue disorders including SLE (8). Rarely, this lesion progresses to a papulonodular rash of the forehead, trunk and upper extremities. $\mathrm{C} 3$ and immunoglobulin $\mathrm{M}$ deposition have also been noted at the dermoepidermal junction. There is no known relationship to immunosuppressive therapy. This rash may be the patient's presenting complaint. Cutaneous manifestations were not noted in our patient. Unfortunately we were unable to assess the specimen for $\mathrm{C} 3$ or immunoglobulin $\mathrm{M}$ deposition due to the method of processing of the tissue postoperatively. A MEDLINE search of articles published from 1966 to June 1988 inclusive by using the text words 'mucinous cystadenoma' or 'mucinous cystadenocarcinoma' and 'lupus erythematosus systemic' failed to reveal any relationship between these lesions. We felt that the lesions occurred coincidentally in the patient; however, speculation that the documented abnormal mucin deposition in the cutaneous tissues of some SLE patients may have played a role in the development of our patient's mucinous cystadenoma is intriguing.

The patient's symptoms completely abated following surgery. We assumed that her symptoms of diarrhea and cramping resulted from partial intussusception of the mucinous cystadenoma of the appendix into the right colon.

The mucosa of the appendix is derived from colonic epithelium and is, therefore, susceptible to the same neoplastic influences as the rest of the lower gastrointestinal tract. An
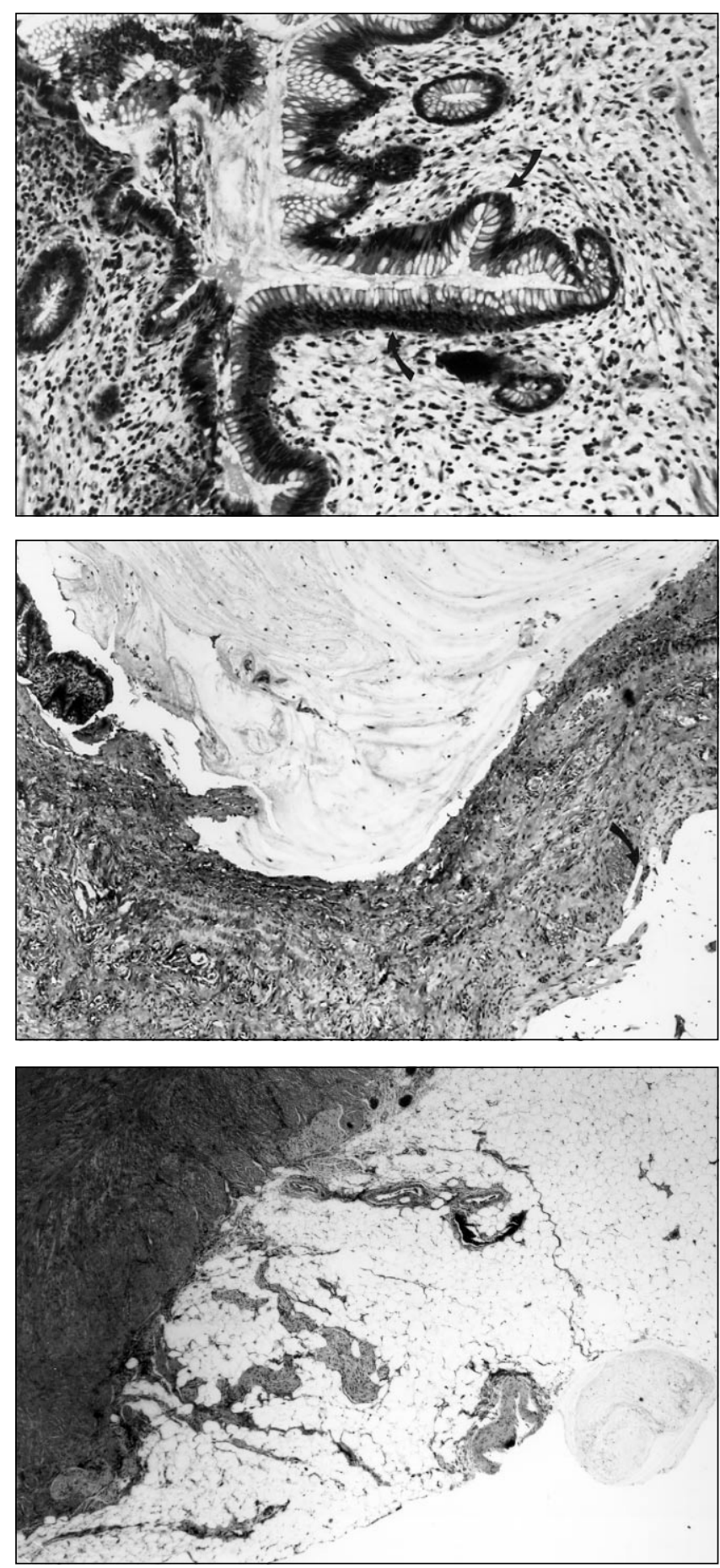

Figure 3) Permanent histology using hematoxylin and eosin staining indicates that the patient's appendix has been partially replaced by mucinous tumours. Top Partial replacement of the appendiceal epithelium by a cytologically bland, mucinous epithelium (black arrow; x100). Middle Mucus is shown within the lumen of the appendix and the submucosa (black arrow; x40). The mucosa is ulcerated in this region. Bottom Mucin pool located in the serosa of the appendix (x20). Failure to identify associated neoplastic cells suggests that this is a cystadenoma dissection rather than a cystadenocarcinoma.

association between mucinous neoplasia of the appendix and synchronous or metachronous neoplasms of the colon has been reported to be in the range of $20 \%(2,4)$. 
In our patient, a single hyperplastic polyp of the transverse colon was identified and removed at colonoscopy. No neoplastic lesions were identified other than the mucinous cystadenoma noted in the cecum. Surveillance colonoscopy should be offered to all patients with known mucinous neoplasms of the vermiform appendix. A MEDLINE review from of articles published from 1966 to June 1998 inclusive revealed two isolated case reports of colonic neoplasia in patients with SLE $(9,10)$. There was no suggestion of an increased incidence of colonic neoplasia in patients with SLE.

\section{REFERENCES}

1. Fujiwara T, Hizuta A, Iwagaki H, et al. Appendiceal mucocele with concomitant colonic cancer. Report of two cases. Dis Colon Rectum 1996;39:232-6.

2. Higa A, Rosai J, Pizzimbono CA, Wise L. Mucosal hyperplasia, mucinous cystadenoma and mucinous cystadenoma of the appendix: A re-evaluation of appendiceal "mucocele". Cancer $1973 ; 32: 1525-41$.
3. Landen S, Bertrand C, Madden GJ, et al. Appendiceal mucoceles and pseudomyxoma peritonei. Surg Gynecol Obstet 1992;175:401-4.

4. Wolff M, Ahmed N. Epithelial neoplasms of the vermiform appendix (exclusive of carcinoid). II. Cystadenomas, papillary adenomas, and adenomatous polyps of the appendix. Cancer 1976;37:2511-22.

5. Qizilbash AH. Mucoceles of the appendix. Their relationship to hyperplastic polyps, mucinous cystadenomas, and cystadenocarcinomas. Arch Pathol 1975;99:548-55.

6. Gibbs NM. Mucinous cystadenoma and cystadenocarcinoma of the vermiform appendix with particular reference to mucocele and pseudomyxoma peritonei. J Clin Pathol 1973;26:413-21.

7. Nitecki SS, Wolff BG, Schlinkert R, Sarr MG. The natural history of surgically treated primary adenocarcinoma of the appendix. Ann Surg 1994;219:51-7.

8. Lee WS, Chung J, Ahn SK. Mucinous lupus alopecia associated with papulonodular mucinosis as a new manifestation of lupus erythematosus. Int J Dermatol 1996;35:72-3. (Lett)

9. Alikhan M, Cumming OW, Rex D. Subtotal colectomy in a patient with collangeous colitis associated with colonic carcinoma and systemic lupus erythematosus. Am J Gastroenterol 1997;92:1213-5.

10. Gemke GR, Bilzens EP, Senina VA. [Bleeding polyp of the transverse colon in a patient with systemic lupus erythematosus]. Klin Med (Mosk) 1983;61:111-2. 


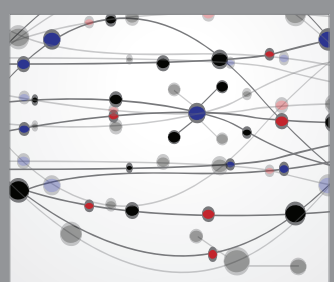

The Scientific World Journal
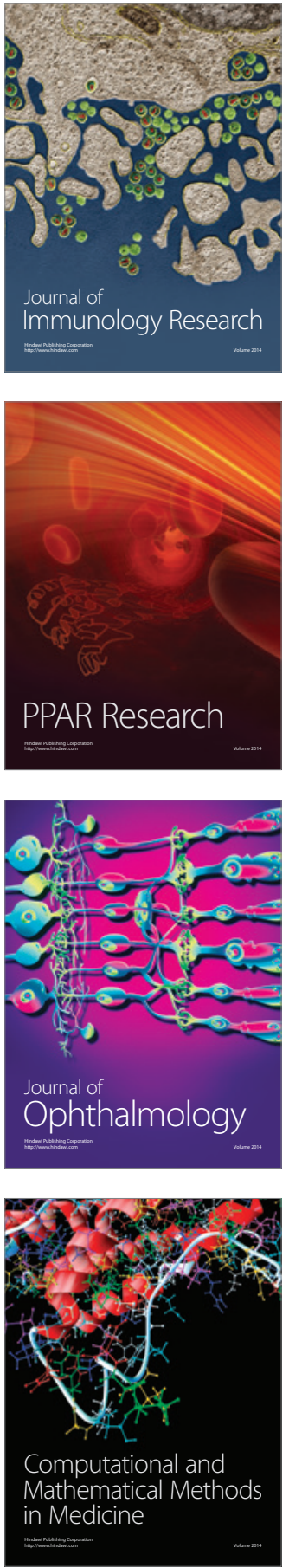

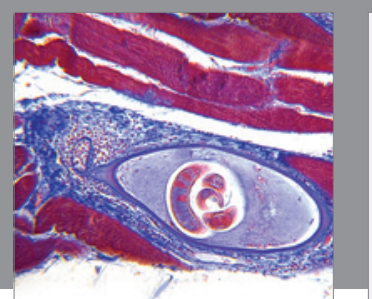

Gastroenterology Research and Practice

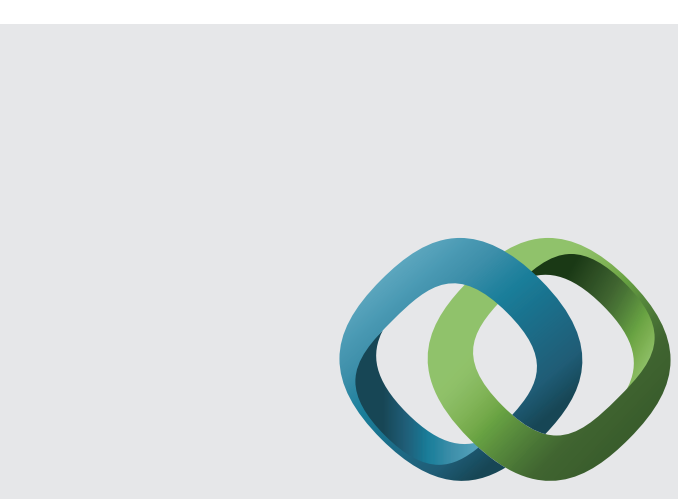

\section{Hindawi}

Submit your manuscripts at

http://www.hindawi.com
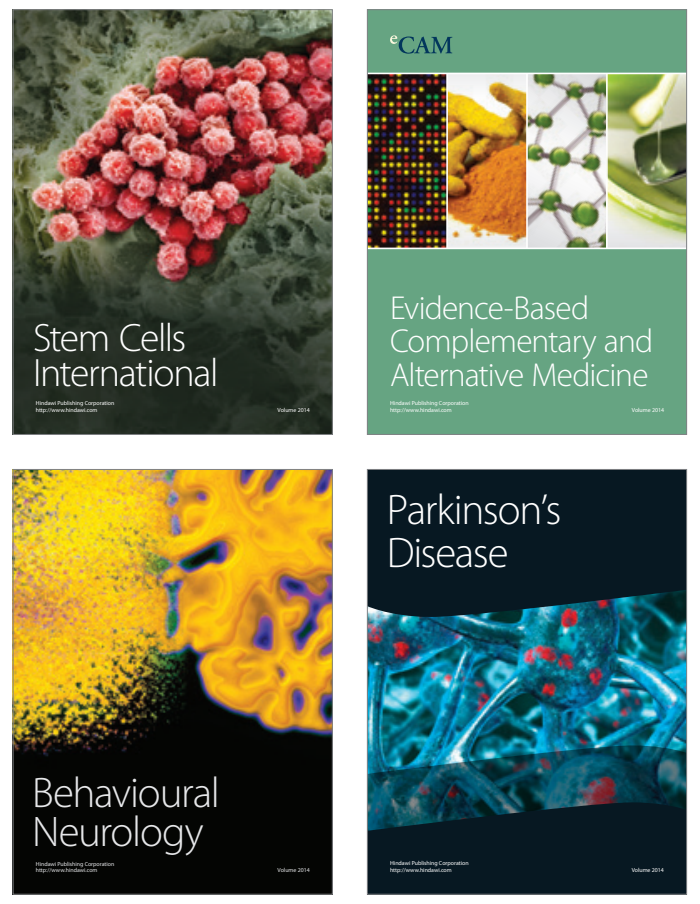
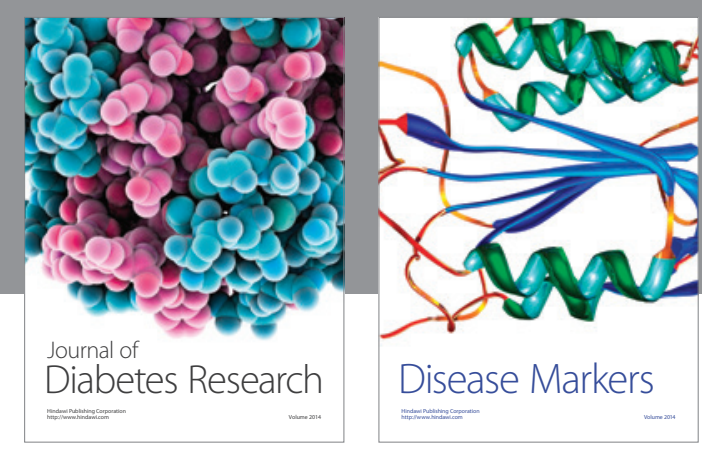

Disease Markers
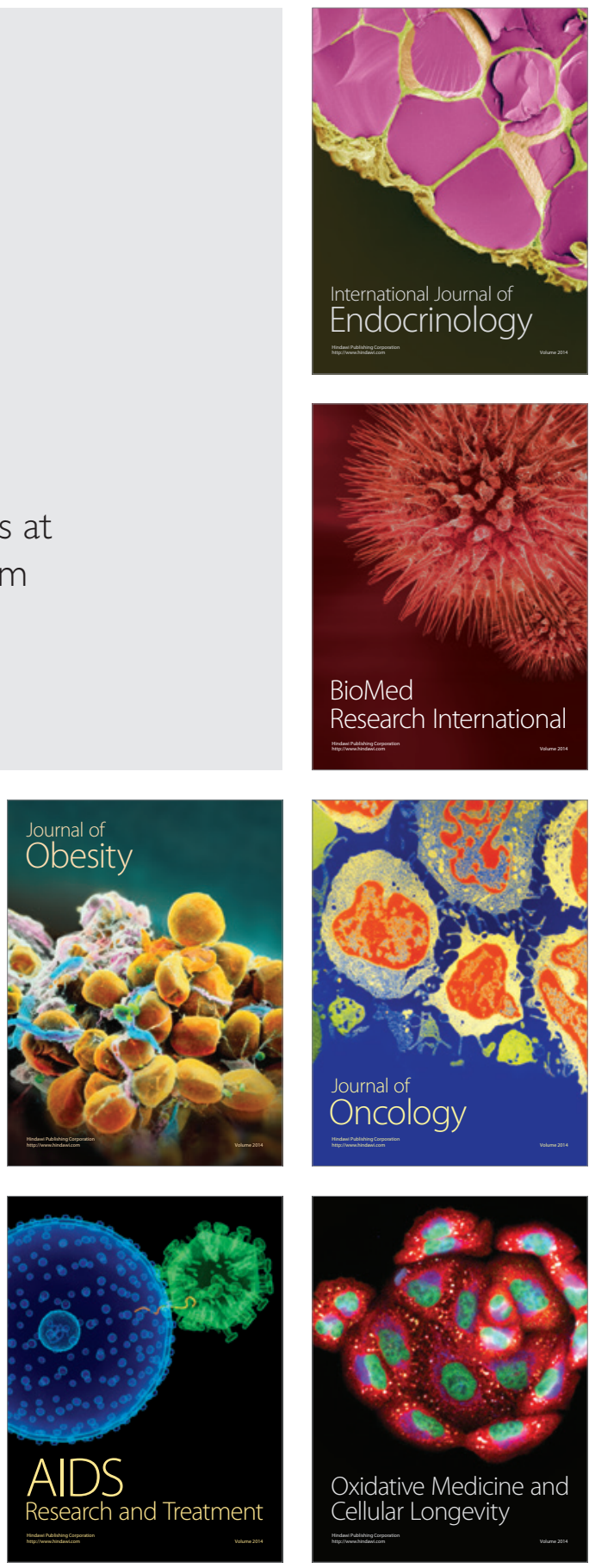